\title{
THE CORRELATION BETWEEN CI-IVC USING USG WITH TBW, CO AND USING NICAS FOR AKI PATIENTS AT EMERGENCY INSTALLATION OF SYAIFUL ANWAR GENERAL HOSPITAL, MALANG
}

\begin{abstract}
Martha Likita Adhiswasti
Medical Emergency of Faculty of Medicine-Syaiful Anwar General Hospital Malang

\section{Abstract}

Background : Acute Kidney Injury (AKI) was a rapid decrease of glomerular filtrate rate, which was generally reversibly, with/without disruption of fluid, and electrolyte balance. Maintaining a constant body fluid volume remains stable was essential for homeostasis to prevent emergencies and avoid death. Assessment and monitoring of intravascular volume status was an integral part of the critical patients management. One of which couldbe assessed through the Caval Index IVC (CI-IVC) using USG and Total Body Water (TBW) as well as Cardiac Output (CO) and Cardiac Index (CI) using Non-Invasive Cardiac System (NICAS), where the rate of AKI was considered high. The purpose of this study was: to determine the relationship between CI-IVC and TBW, CO, and CI in AKI patients. Research methods : An observational analytic study was conducted with a cross-sectional approach of 60 samples in the Emergency Installation of Syaiful Anwar General Hospital Malang from January to December 2018. Result: The results showed that all relationships between TBW and IVC and CO and CI meet the linearity requirements, with R2 respectively as follows: $0.0969 ; 0.1062 ; 0.0325$.
\end{abstract}

CThere is a mutual relationship between CI-IVC using USG and TBW, CO and CI using NICAS in AKI patients. Keywords: CI-IVC, USG, TBW-CO-CI, NICAS, AKI

DOI: $10.7176 / \mathrm{JHMN} / 76-11$

Publication date:June 30th 2020

\section{INTRODUCTION}

Conceptually, Acute Kidney Injury (AKI) is a rapid decrease of glomerular filtrate rate, which generally is reversible, followed by kidney failure to excrete residual nitrogen metabolism, with/without impaired fluid and electrolyte balance). The best prevention of AKI is to pay attention to the hemodynamic status, maintain fluid balance, and prevent the use of nephrotoxic substances or drugs that can interfere with kidney function. Keeping the volume of body fluids relatively constant, and the stable electrolyte composition is essential for homeostasis. Fluid and electrolyte disturbances can bring patients into an emergency that can cause death if not managed quickly and appropriately. Assessment and monitoring of intravascular volume status is an essential part of critical patient management. Intravascular volume status can be assessed through physical examination, biochemical markers, tissue perfusion, Central Venous Pressure (CVP), sonographic assessment of Caval Index IVC (CI-IVC), Cardiac Output (CO), and Cardiac Index (CI) of patients. Assessment of IVC diameter and diameter variation is one of the noninvasive techniques that can be used to assess the status of intravascular fluid or the patient's response to fluid administration, where the use of ultrasound is not only mobile, easy to use, and relatively cheap. The Non-Invasive Cardiac System (NICaS), which is a computerized device, is connected with electrodes to one hand and foot to assess Stroke Volume, Cardiac Output, Total Peripheral Resistance, Cardiac Power Index, LV Systolic Function, Total Body Water, Respiration Rate, and 1 ECG Channel. Considering the backgrounds of AKI patients, especially those with haemodynamic disorders, the Caval Index Inferior Vein Cava (CI-IVC) on USG, and Total Body Water (TBW), Cardiac Output (CO), Cardiac Index (CI) can be seen through the NICaS tool. Therefore, researchers are interested in conducting further research to find out the correlation between CI-IVC and TBW, CO, and CI in AKI patients using USG and NICaS.

\section{LITERATURE REVIEW}

Kidney (Ren) is an organ that has an essential role in regulating the balance of water and metabolites in the body and maintaining the balance acid-base in the blood. Residual products in the urine form will leave the kidneys into the urinary tract and be removed from the body. The kidneys are located behind the peritoneum, so they are called retroperitoneal organs. A study says that about $95 \%$ will develop into AKI due to several previous comorbidities: $9.08 \%$ of the aggravate previous disease, $5 \%$ due to degenerative age, $4.5 \%$ due to the use of vasopressors, $41.5 \%$ due to sepsis/SIRS, $33.3 \%$ due to hypotension/shock, $2.34 \%$ due to high risk of surgery, 
$20.5 \%$ due to heart failure, $1.58 \%$ due to diabetes mellitus, $15.3 \%$ due to the use of nephrotoxic drugs, $14.3 \%$ due to hypertension, and $14.0 \%$ due to blood creatinine level problems (Elsevier, et al., 2017). ADQI issued an AKI classification system with RIFLE criteria consisting of 3 categories (based on increasing serum Cr levels or decreasing LFG or UO criteria) that describe the severity of kidney function decline and two categories that describe the prognosis of renal impairment.

\section{Etiology}

The etiology of AKI is divided into three main groups based on the pathogenesis of AKI: (1) disease that causes renal hypoperfusion without causing interference with the renal parenchyma (prerenal AKI:55\%); (2) diseases that directly cause kidney parenchymal disorders (renal/intrinsic AKI:40\%); (3) diseases associated with urinary tract obstruction (AKR post renal:5\%). The number of events that cause AKI is very dependent on the location of the AKI.

\section{Gambar 2.4. Lamanya Terjadi AKI Dengan Kadar Serum Kreatinin}

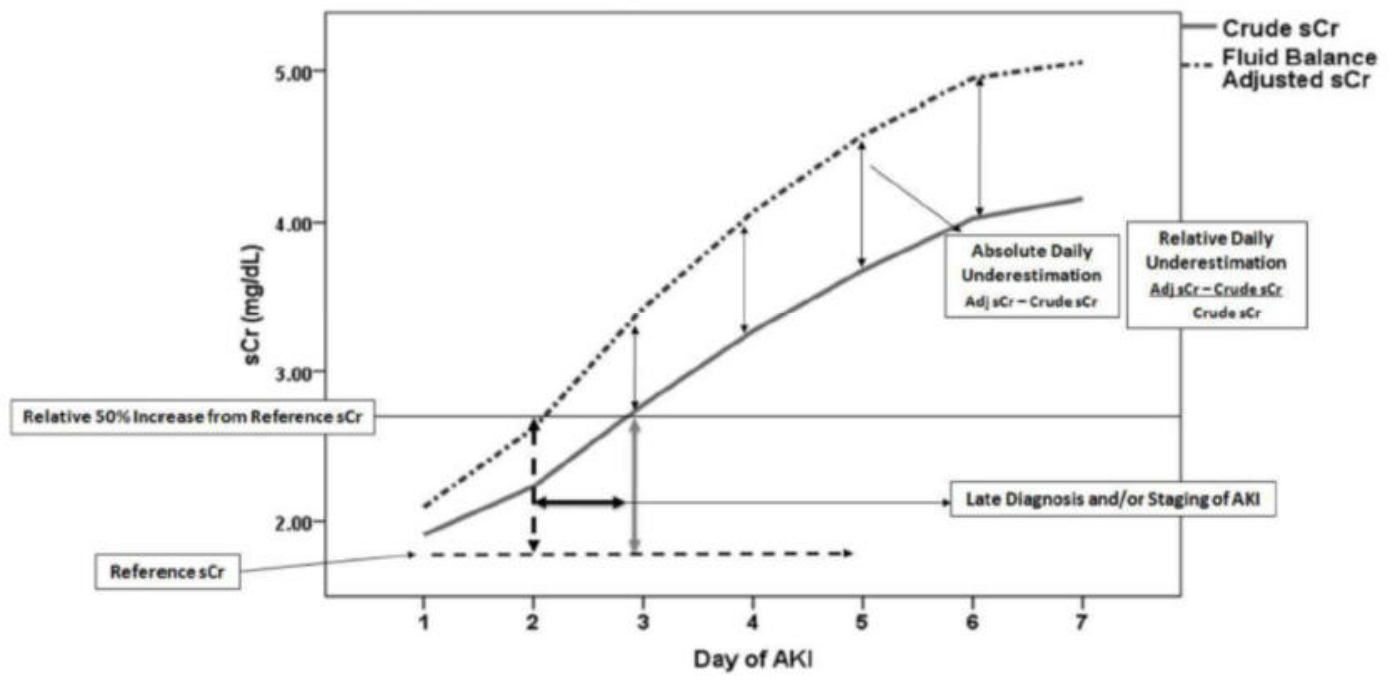

\section{Fluid Imbalance}

Fluid imbalances include two primary groups, namely isotonic and osmolar disorders. An isotonic imbalance occurs when several fluids and electrolytes disappear together in balanced proportions. Meanwhile, osmolar imbalance occurs when fluid loss is not offset by changes in electrolyte levels in balanced proportions, causing changes in serum concentration and osmolality. Therefore, there are four categories of fluid imbalances: (a) Loss of isotonic fluid and electrolytes, (b) Loss of fluid (only reduced water), (c) isotonic fluid and electrolytes increase, and (d) osmolality increase (only increased water).

\section{Fluid Volume Deficit}

Fluid volume deficits occur when the body loses proportional (isotonic) amounts of extracellular fluid and electrolytes. This condition is also called hypovolemia. Generally, this disorder is preceded by loss of intravascular fluid, followed by the transfer of intercellular fluid to intravascular, causing a decrease in extracellular fluid. To be able to compensate for this condition, the body transfers intracellular fluid. In general, fluid volume deficits are caused by several things; loss of abnormal fluid through the skin, decrease in fluid intake, bleeding and movement of fluid to the third location (the location where the fluid moves and it is not easy to return to its original location under resting extracellular fluid). Fluid can move from intravascular locations to potential locations such as pleura, peritoneum, pericardium, or joint cavity. Besides, certain conditions, such as trapping fluid in the digestive tract is possibly caused by obstruction of the digestive tract.

\section{Cardiac Output}

The concept of cardiac output is best explained by the equation CO = HR X SV where (CO: Cardiac Output) is the function of (HR: Heart Rate) X (SV:Stroke Volume). Heart frequency is a function of the autonomic nervous system. If cardiac output is reduced, the sympathetic nervous system will accelerate the frequency of the heart to maintain cardiac output. If the compensatory mechanism to maintain adequate tissue perfusion, so the 
volume of the heart's stroke must adjust to maintain cardiac output. However, in case of heart failure with the main problem of damage and stiffness of the heart muscle fibers, the stroke volume is reduced, and normal cardiac output can still be maintained. The volume of the stroke and the amount of blood pumped at each contraction depend on three factors; preload, contractility, and afterload.

\section{Cardiac Index (CI)}

It is a hemodynamic parameter that connects cardiac output $(\mathrm{CO})$ from the left ventricle in one minute to the surface area of the body (BSA), aiming to connect the heart's performance with individual size. The unit of measurement is liters per minute per meter square $(\mathrm{L} / \mathrm{min} / \mathrm{m} 2)$. The normal CI range at rest is $2.6-4.2 \mathrm{~L} / \mathrm{min} / \mathrm{m} 2$. This CI is often used in intensive care and intensive care of the heart. As a useful marker of how well the heart functions as a pump by directly connecting the volume of blood pumped by the heart to the surface area of a person's body. If the CI falls suddenly below $2.2 \mathrm{~L} / \mathrm{min} / \mathrm{m} 2$, the patient inevitably has a cardiogenic shock.

\section{Assessment and Monitoring of Intravascular Volume Status}

Assessment and monitoring of intravascular volume status is an essential part of critical patient management. Intravascular volume status can be assessed through physical examination, vital sign examination, measurement of biochemical markers, tissue perfusion, central venous pressure (CVP), and sonographic assessment of inferior vena cava diameter (IVC). Noninvasive methods have become another alternative and evolved to become a popular method of assessing a patient's fluid status. The diameter assessment (CI-IVC) and its diameter variation become a noninvasive technique to assess the status of intravascular fluid and the patient's response to fluid administration. Excessive fluid resuscitation increases the days to stay at ICU and hospitals as well as increases mortality. The same thing is found in septic shock patients (Marik et al., 2011).

\section{Non-Invasive Cardiac System (NICaS)}

The NICaS tool in the form of a new computerized non-invasive tool is for measuring hemodynamic parameters and total body fluids using cardiographic impedance techniques. Based on the theory, changes in blood volume in the aorta and fluid content in body tissues will change impedance to estimate stroke volume and adequacy of body fluids. Some initial studies revealed a good correlation between hemodynamic measurements using the NICaS tool and thermodilution measurements, as the gold standard. This tool is connected to the monitor by entering the patients' data and their pathological condition. Later on, connect the leads on the chest and one of the right or left legs as well as one of the right or left hand connected by electrodes to one hand and foot. After 10 minutes, the results will come out on the monitor, appearing Stroke Volume graph, Cardiac Output, Total Peripheral Resistance, Cardiac Power Index, LV Systolic Function, Total Body Water, Respiration Rate, and 1 Channel ECG.

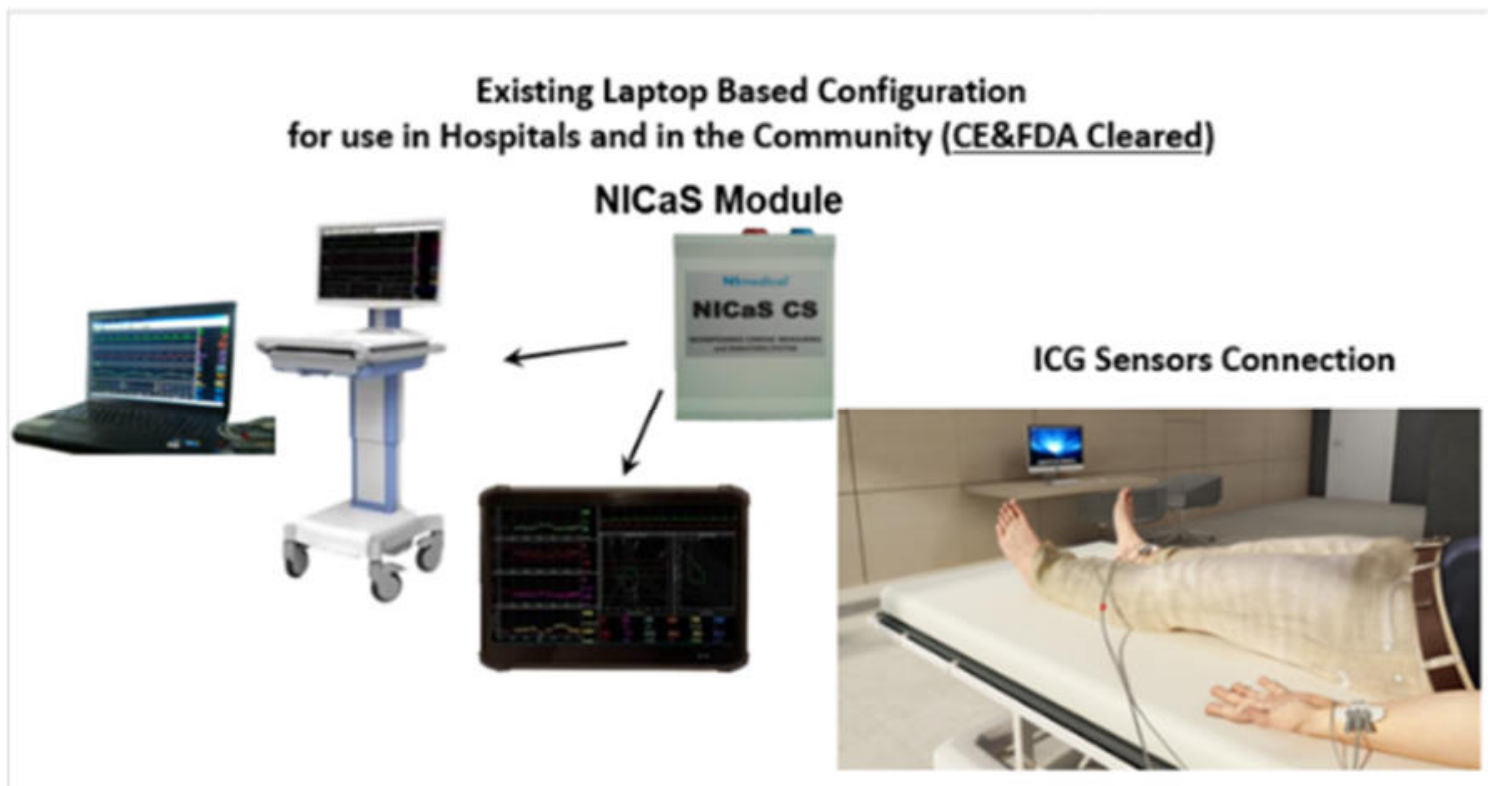


NICaS Results in Monitors

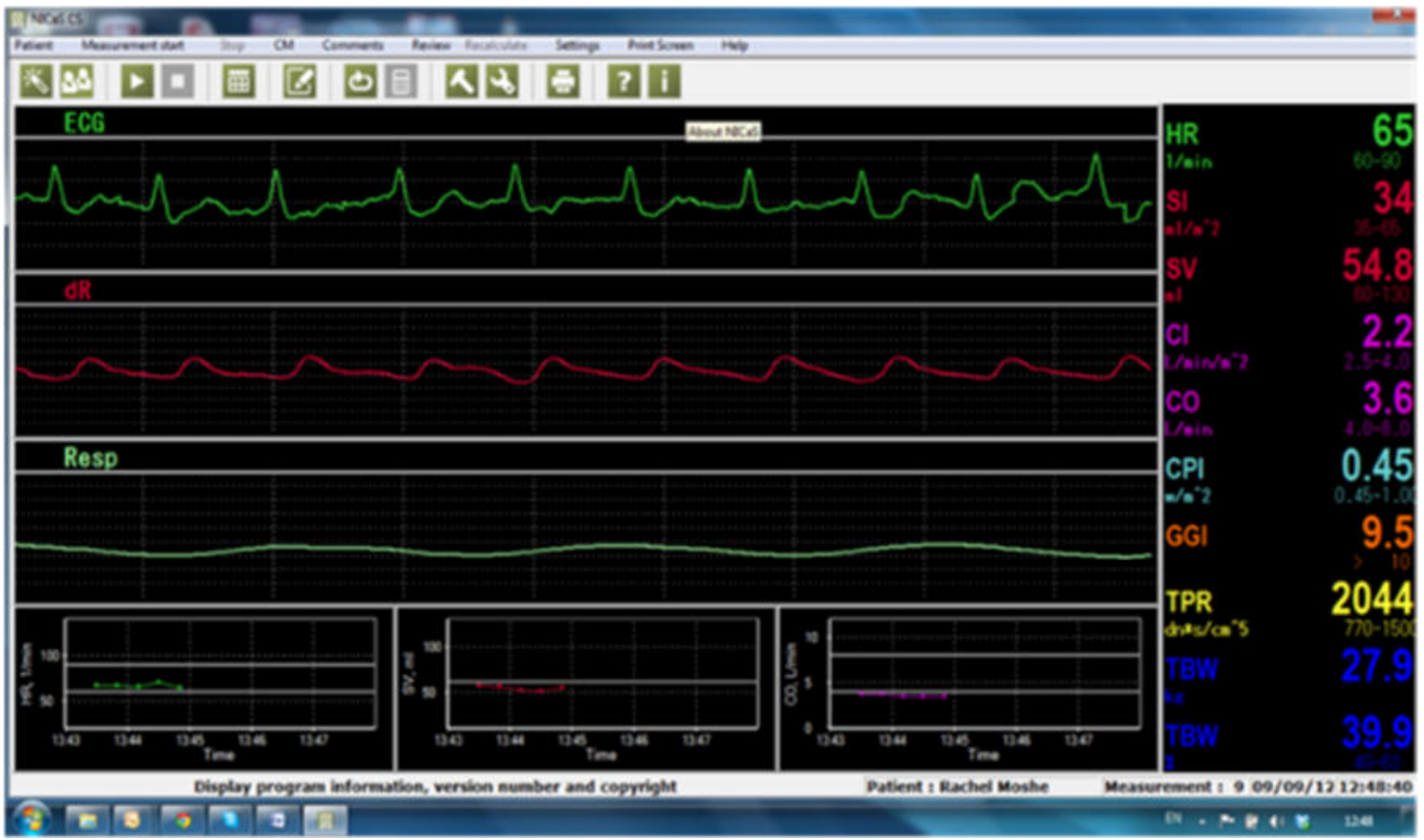

Hypothesis NICaS.

There is a correlation between CI-IVC against TBW, CO, and CI againsta AKI patients using USG and

\section{Research design}

The research was an observational analytic study with a cross-sectional approach to examine the relationship between CI-IVC against TBW, CO, and CI against AKI patients using USG and NICaS.

\section{Population}

Location: Emergency Installation of Syaiful Anwar General Hospital Malang

Time : January-December 2018, the population was all AKI Prarenal patients who came to the Emergency Installation of Syaiful Anwar General Hospital Malang. The samples were 60 patiens determined using the consecutive technique.

\section{Data Collection and Procedure}

Primary data were taken from observations of the hemodynamic status of AKI patients seen from serum blood creatinine levels, CI-IVC, TBW, CO, and CI in the Emergency Installation. All data collected from the Emergency Installation participating in the study were collected during the study period. Initial subject data, including identity, clinical condition, other illnesses, laboratory results, and readings of CI-IVC, TBW, CO, and CI, were recorded. The data obtained was recorded, collected, and analyzed.

\section{Data analysis}

Data analysis was performed with the Pearson correlation test, with a 95\% confidence level, $\alpha=0.05$; significant if $\mathrm{p}<0.05$.

\section{RESULTS AND ANALYSIS OF RESEARCH DATA}

Data collection was carried out for 12 months during January-December 2018 period at the dr.Saiful Anwar General Hospital. Every patient who met the inclusion and exclusion criteria should have prerenal AKI 
diagnosis, assessed by CI-IVC via USG, and TBW, CO, and CI through NICaS. Informed consent and statement of consent were made to all samples and the patient's family in accordance with existing ethical rules. A total of 60 AKI patients who met the inclusion and exclusion criteria were taken as the study sample.

\section{Distribution Frequency}

Distribution Frequency included age, height, weight, blood creatine levels, body surface area (BSA), body mass index (BMI), total body water (TBW), caval index (CI-IVC), cardiac output (CO), and cardiac index (CI) depicted in the table.

\section{Tabel 5.1 Karakteristik Pasien AKI}

\begin{tabular}{|c|c|c|c|}
\hline No. & Karakteristik & Jumlah & Persentase $(\%)$ \\
\hline \multirow[t]{3}{*}{1.} & Jenis Kelamin & & \\
\hline & Laki-laki & 40 & 67 \\
\hline & Perempuan & 20 & 33 \\
\hline \multicolumn{4}{|c|}{ 2. Usia } \\
\hline & $40-50$ & 15 & 25 \\
\hline & $50-60$ & 17 & 28 \\
\hline & $>60$ & 28 & 47 \\
\hline \multicolumn{4}{|c|}{ 3. $\mathrm{TB}$} \\
\hline & $<150$ & 4 & 7 \\
\hline & $150-160$ & 25 & 42 \\
\hline & $>160$ & 31 & 51 \\
\hline \multirow[t]{4}{*}{4.} & BB & & \\
\hline & $<50$ & 12 & 20 \\
\hline & $50-60$ & 22 & 37 \\
\hline & $>60$ & 26 & 43 \\
\hline \multirow[t]{4}{*}{5.} & Kreatinin Darah & & \\
\hline & $50-99$ & 18 & 30 \\
\hline & $100-149$ & 28 & 47 \\
\hline & $>150$ & 14 & 23 \\
\hline \multirow[t]{4}{*}{6.} & BSA & & \\
\hline & $<1.49$ & 15 & 25 \\
\hline & $1.50-2.10$ & 40 & 67 \\
\hline & $>2.10$ & 5 & 8 \\
\hline \multirow[t]{4}{*}{7.} & BMI & & \\
\hline & $<18$ & 8 & 13 \\
\hline & $18-30$ & 42 & 70 \\
\hline & $>30$ & 10 & 17 \\
\hline \multirow[t]{4}{*}{8.} & TBW & & \\
\hline & kurang & 5 & 8 \\
\hline & normal & 9 & 15 \\
\hline & lebih & 46 & 77 \\
\hline \multirow[t]{4}{*}{9.} & IVC & & \\
\hline & $<15$ & 8 & 13 \\
\hline & $15-25$ & 37 & 67 \\
\hline & $>25$ & 15 & 25 \\
\hline \multirow[t]{4}{*}{10.} & $\mathrm{CO}$ & & \\
\hline & $<4$ & 19 & 32 \\
\hline & $4-8$ & 33 & 55 \\
\hline & $>8$ & 8 & 13 \\
\hline \multirow[t]{4}{*}{11.} & $\mathrm{CI}$ & & \\
\hline & $<2.5$ & 22 & 37 \\
\hline & $2.5-4$ & 28 & 47 \\
\hline & $>4$ & 10 & 16 \\
\hline \multirow[t]{6}{*}{12.} & Penyakit Penyerta & & \\
\hline & Diare & 12 & 20 \\
\hline & Sepsis & 25 & 41 \\
\hline & Muntah-muntah & 9 & 15 \\
\hline & $\mathrm{ADHF}$ & 8 & 14 \\
\hline & Hiperglikemia krisis & 6 & 10 \\
\hline
\end{tabular}

The results showed that all relationships between TBW and IVC, CO and CI met the linearity requirements, with R2 respectively as follows: $0.0969 ; 0.1062 ; 0.0325$, meaning that the relationship between TBW and IVC, TBW 
and $\mathrm{CO}$, and TBW and each CI, can only be explained about $9.69 \% ; 10.62 \%, 3.25 \%$ while other variables cause $90.31 \% ; 89.32 \%$ and $96.75 \%$ of the relationship. After that, the correlation test could be done. If one of the variables/both was usually distributed, the statistical test used was the Pearson correlation test. All relationships between IVC and CO and CI satisfy the linearity requirements, with each R2 as follows: 0.7009 and 0.676 mean the relationship between IVC and CO and IVC and CI could be explained by about $70.09 \%$ and $67.6 \%$, while other variables cause $29.91 \%$ and $32 \%$ of the relationship. Result :

Tabel 5.3 Korelasi Hubungan Antara CI-IVC terhadap TBW, CO, dan CI

\begin{tabular}{ccccccc}
\hline Variabel & \multicolumn{2}{c}{ TBW } & \multicolumn{2}{c}{ CO } & \multicolumn{2}{c}{ CI } \\
\hline CI-IVC & $\mathrm{p}$ & $\mathrm{r}$ & $\mathrm{p}$ & $\mathrm{r}$ & $\mathrm{p}$ & $\mathrm{r}$ \\
& 0.010 & 0.331 & 0.000 & 0.837 & 0.000 & 0.822 \\
\hline
\end{tabular}

1. There was a significant correlation between CI-IVC and TBW ( $\mathrm{p}=0.010, \mathrm{r}=0.331$ ) with a positive and moderate relationship. This means that the higher the CI-IVC, the higher the TBW.

2. There was a significant correlation between CI-IVC and CO $(p=0.000, r=0.837)$ and CI-VC and CI $(p=0.000$, $\mathrm{r}=0.822$ ) with a positive and strong relationship. This means that the higher the CI-IVC, the higher the CO and CI.

\section{A. DATA DESKRIPTIF}

\section{A.1 Ukuran Sentral Tendensi}

\begin{tabular}{|c|c|c|c|c|c|c|c|}
\hline \multicolumn{8}{|c|}{ Statistics } \\
\hline & \multicolumn{2}{|c|}{$\mathrm{N}$} & \multirow[t]{2}{*}{ Mean } & \multirow[t]{2}{*}{ Median } & \multirow{2}{*}{$\begin{array}{c}\text { Std. } \\
\text { Deviation }\end{array}$} & \multirow[t]{2}{*}{ Minimum } & \multirow[t]{2}{*}{ Maximum } \\
\hline & Valid & Missing & & & & & \\
\hline BSA_m2 & 60 & 0 & 1.6547 & 1.6550 & .20729 & 1.27 & 2.19 \\
\hline Umur_tahun & 60 & 0 & 60.98 & 59.50 & 13.271 & 27 & 95 \\
\hline BMI_kgperm2 & 60 & 0 & 23.6207 & 22.0650 & 4.44369 & 16.00 & 37.01 \\
\hline TBW_ & 60 & 0 & 43.223 & 41.500 & 14.4026 & 19.0 & 79.0 \\
\hline TBW_persen & 60 & 0 & 70.4992 & 67.5150 & 18.01592 & 35.08 & 112.08 \\
\hline IVC_mm & 60 & 0 & 18.25 & 18.00 & 6.534 & 5 & 30 \\
\hline CO_LperMin & 60 & 0 & 5.920 & 5.400 & 2.5610 & 1.8 & 14.3 \\
\hline $\mathrm{Cl}$ LperMinperm2 & 60 & 0 & 3.548 & 3.350 & 1.3180 & 1.1 & 7.6 \\
\hline
\end{tabular}

Tests of Normality

\begin{tabular}{|l|r|r|r|r|r|r|}
\hline & \multicolumn{3}{|c|}{ Kolmogorov-Smirnov } & \multicolumn{3}{|c|}{ Shapiro-Wilk } \\
\cline { 2 - 7 } & Statistic & Df & Sig. & Statistic & \multicolumn{1}{c|}{ Df } & Sig. \\
\hline BSA_m2 & .093 & 60 & $.200^{\circ}$ & .979 & 60 & .400 \\
Umur_tahun & .074 & 60 & $.200^{\circ}$ & .989 & 60 & .871 \\
TBW_kg & .093 & 60 & $.200^{\circ}$ & .981 & 60 & .469 \\
TBW_persen & .088 & 60 & $.200^{\circ}$ & .983 & 60 & .576 \\
IVC_mm & .165 & 60 & .000 & .942 & 60 & .006 \\
CO_LperMin & .098 & 60 & $.200^{\circ}$ & .947 & 60 & .011 \\
CI_LperMinperm2 & .098 & 60 & $.200^{\circ}$ & .962 & 60 & .056 \\
BMI_kgperm2 & .168 & 60 & .000 & .934 & 60 & .003 \\
\hline
\end{tabular}

$\because$. This is a lower bound of the true significance.

Correlations

\begin{tabular}{|l|r|r|r|}
\hline Variabel & IVC $\mathrm{mm}$ & CO_LperMin & Cl_LperMinperm2 \\
\hline \multirow{3}{*}{ TBW_kg } & .331 & .335 & .193 \\
\cline { 2 - 4 } & .010 & .009 & .140 \\
\cline { 2 - 4 } & 60 & 60 & 60 \\
\hline
\end{tabular}

\begin{tabular}{|l|r|r|r|}
\hline \multirow{3}{*}{ IVC_mm } & 1 & .837 & .822 \\
\cline { 2 - 4 } & & .000 & .000 \\
\cline { 2 - 4 } & 60 & 60 & 60 \\
\hline \multirow{3}{*}{ CO_LperMin } & .837 & 1 & .939 \\
\cline { 2 - 4 } & .000 & & .000 \\
\cline { 2 - 4 } & 60 & 60 & 60 \\
\hline
\end{tabular}




\section{DISCUSSION}

\section{The correlation between CI-IVC and TBW in AKI patients}

The results of CI-IVC against TBW, with p: $0.010 ; \mathrm{r}$ : 0.331, indicates that there is a significant correlation with moderate strength, where the higher the CI-IVC, the higher the TBW. Based on data of the AKI patients' characteristics, the highest CI-IVC at $15-25 \mathrm{~mm}$ (normal) was $67 \%$, CI-IVC more than $25 \mathrm{~mm}$ was only 15 people or $25 \%$, and the highest TBW by 46 people (77\%). Macedo et al. (2010) reveal that the duration of AKI was directly proportional to the increase in serum creatine and TBW. It happens mostly to resuscitation of sepsis patients or other conditions that emit many body fluids, such as burns, pancreatitis, cancer both running chemotherapy and bone marrow transplantation. An increase in TBW can reach $10 \%$ in 72 hours. Meanwhile, other studies say that the higher the TBW, the higher the serum creatine levels, affecting the severity of kidney function. Adult female TBW is smaller than in male adults of the same age. The results revealed that the TBW found in an adult man was 40 people (67\%), and a woman was only 20 people (33\%). For some reason, obesity and age addition will reduce the total body water content. In this study, the majority of the object's age was over 60 years (47\%), with the most weight more than $60 \mathrm{~kg}(43 \%)$, and the majority of BSA and BMI was standard $(1.5-2.10)$ and (18-30), or $67 \%$ and $70 \%$. Factors affecting an increase in daily fluid requirements are fever, hyperventilation, high ambient temperature, and loss of abnormal fluids such as diarrhea or polyuria. Data shows that most complaints from patients are hyperglycemia and shock sepsis, causing dehydration. Pathophysiology, mainly due to hypovolemia, dehydration, diarrhea, vomiting, hyperglycemia, or hypoalbumin in sepsis patients, result in increased sympathetic, increased parasympathetic, or increased stroke volume, decreased preload, and increased preload. Renal perfusion pressure decrease will reduce cardiac output and cardiac index; thus, the reninangiotensin-aldosterone system was activated, and peripheral resistance increased. Therefore, blood flow to the kidneys is also lost, causing GFR to decrease, and the blood sodium levels resist. Besides, there is also a decrease in renal sodium and water excretion. Also, the body fluid movement was disrupted, affecting edema and fluid overload.

\section{The correlation between CI-IVC against $\mathrm{CO}$ and CI against AKI patient.}

It was stated that there was a positive ad strong relationship between CI-IVC and CO $(\mathrm{p}=0.000, \mathrm{r}=$ $0.837)$ and CI-VC and CI $(\mathrm{p}=0.000, \mathrm{r}=0.822)$. This means that the higher the CI-IVC, the higher the CO and CI. CI-VCI diameter of less than $15 \mathrm{~mm}$ indicates body fluid depletion. CI-VCI diameter of more than $25 \mathrm{~mm}$ indicates a fluid overload (Sridhar et al, 2012). An increase in CI-IVC illustrates that the diameter of venous vessels, for AKI patients with fluid overload, transversely from the right heart widens. However, the increased CI value may be caused by several factors; AKI patients should have decreased $\mathrm{CO}$ value due to renal hypoperfusion, affecting the decrease in CI value. However, data collected by researchers showed that from 60 patients, it turns out that only 19 people (32\%) having CO less than 4, the most are standard CO (4-8) or around 33 people (55\%), those having CI less than 2.5 are only 22 people (37\%), and the highest number is standard CI (2.5-4) by 28 people $(47 \%)$. Meanwhile, based on the precise pathophysiology, there is a tissue hypoperfusion, which indirectly affects AKI. CO and CI should decrease indeed, and the highest $\mathrm{CO}$ and $\mathrm{CI}$ values of $60 \mathrm{AKI}$ patients are normal. Preload is one of the main determinants of CO (Sabatier et al., 2012). Preload has been defined as the maximum level of myocardial fiber tension before ventricular contraction and is determined by the mean length of sarcomere at the end of diastole. Therefore, the end-diastolic ventricular volume is accepted by consensus as a synonym for preload, and, at its turn under normal conditions, intracardiac pressure is taken to be a substitute for intracardiac volume. Besides, preload is also related to CI-IVC where the higher the CI-IVC, the higher the preload. This is also supported by research by Juhl-Olsen, Frederiksen and Sloth, where the higher the cardiac preload, the higher the cardiac output, but CI-IVC is strongly influenced by the position of the patient (Juhl-Olsen, Frederiksen and Sloth, 2011). This matter was also proven, where there was a significant correlation between IVC and CO $(p=0.000, r$ $=0.837)$. This means that the higher the CI-IVC, the higher the CO and CI. The data we obtained from CI-IVC came from USG and CO from NICaS. Seeing this, the theory and several studies are very supportive of the results of this study. NICaS has the opportunity to replace USG.

\section{Conclusion}

From the data analysis and discussion of the combined correlation between CI-IVC against TBW, CO, and CI against prerenal AKI patients, several conclusions add to knowledge about the prediction of AKI's hemodynamic status patients. Those conclusions include the following: 
1. The combined relationship between CI-IVC and TBW, CO and CI has a powerful relationship to the prognosis of hemodynamic status. Therefore, these four modalities can be used by medical personnel according to the needs and equipment in the hospital.

2. CI-IVC has a significant relationship with the hemodynamic status prognosis of AKI patients. It can be used as an additional examination in addition to TBW, CO, and CI in determining or predicting the hemodynamic status of AKI patients. On the other hands, examination of serum urea creatine is still used as a Gold Standard for AKI diagnostics. For that matter, CI-IVC examination can estimate TBW, CO, and CI in AKI patients. Moreover, there is some sophisticated ultrasound that can measure the patient's $\mathrm{CO}$ and CI, so that it can assess the patient's hemodynamic status objectively. Accordingly, ultrasound is required at Emergency Installation but NICaS, since not yet available in Indonesia, cannot be used.

\section{REFERENCES}

Abuelo JG, Normotensive ischemic acute renal failure.N Engl J Med, 2007; 357:797-805.

Bagshaw SM, George C, Bellomo R.A comparison of the RIFLE and AKIN criteria for acute kidney injury in critically ill patients.Nephrol Dial Transplant.2008;23:1569-74.

Bellomo R, Ronco C., Indications and criteria for initiating renal replacement therapy in the intensive care unit.Kidney Int.1998; 53(66):S106-9.

Coca SG, Parikh CR.Urinary biomarkers for acute kidney injury: perspectives on translation.Clin J Am Soc Nephrol.2008;3:481490,

De Lorenzo, R., Morris, M., Williams, J., Haley, T., Straight, T., Holbrook-Emmons, V. and Medina, J.Does a Simple Bedside Sonographic Measurement of the Inferior Vena Cava Correlate to Central Venous Pressure?.The Journal of Emergency Medicine, (2012 42(4), pp.429-436.).

Himmelfarb J, Joannidis M, Molitoris B, Schietz M, Okusa MD, Warnock D, et al., Evaluation and initial management of acute kidney injury.Clin J Am Soc Nephrol.2008;3:962-7

Jambeih, R., Keddissi, J. and Youness, H.IVC Measurements in Critically Ill Patients with Acute Renal Failure.Critical Care Research and Practice, (2017, 2017, pp.1-6.).

Juhl-Olsen, P., Frederiksen, C. and Sloth, E.Ultrasound Assessment of Inferior Vena Cava Collapsibility Is Not a Valid Measure of Preload Changes During Triggered Positive Pressure Ventilation:A Controlled Cross-Over Study.Ultraschall in der Medizin - European Journal of Ultrasound, 33(02), (2011, pp.152-159.).

Kaptein, M., Kaptein, J., Oo, Z. and Kaptein, E.Relationship of inferior vena cava collapsibility to ultrafiltration volume achieved in critically ill hemodialysis patients.International Journal of Nephrology and Renovascular Disease, Volume 11, (2018; pp.195-209.).

Loekman JS.2008.p.13-17, Vasoactive drugs and the kidney.Dalam:Dharmeizar, Marbun MBH, editor.Makalah lengkap the 8th Jakarta nephrology \& hypertension course and symposium on hypertension.Jakarta:PERNEFRI;

Macedo, E., Bouchard, J., Soroko, S., Chertow, G., Himmelfarb, J., Ikizker, T., Paganini, E. and Mehta, R.Fluid accumulation, recognition and staging of acute kidney injury in critically-ill patients.Critical Care, $(2010,14(3)$, p.R82.).

Mohani CI.Diuretika pada kasus dengan oligouria.Dalam Dharmeizar, Marbun MBH, editor.Makalah lengkap the 8th Jakarta nephrology \& hypertension course and symposium on hypertension.Jakarta:PERNEFRI; 2008.p.9-10,

Patil, S., Jadhav, S., Shetty, N., Kharge, J., Puttegowda, B., Ramalingam, R. and Cholenahally, M.Assessment of inferior vena cava diameter by echocardiography in normal Indian population:A prospective observational study.(2016).

Roesli RMA.Epidemiologi gangguan ginjal akut.Dalam Roesli RMA, Gondodiputro RS, Bandiara R, editor.Diagnosis dan pengelolaan gangguan ginjal akut.Bandung:Pusat Penerbitan Ilmiah Bagian Ilmu Penyakit Dalam FK UNPAD/RS dr.Hasan Sadikin; 2008.p.27-40, 2008.p.41-66; 79-96.

Sabatier, C., Monge, I., Maynar, J. and Ochagavia, A.Assessment of cardiovascular preload and response to volume expansion.Medicina Intensiva (English Edition), (2012; 36(1), pp.45-55.). 
Sja'bani M, Penggunaan manitol: dampaknya pada ginjal.Dalam Dharmeizar, Marbun MBH, editor.Makalah lengkap the 8th Jakarta nephrology \& hypertension course and symposium on hypertension.Jakarta:PERNEFRI; 2008.p.21-22,

Taniguchi, T., Ohtani, T., Nakatani, S., Hayashi, K., Yamaguchi, O., Komuro, I. and Sakata, Y..).Impact of Body Size on Inferior Vena Cava Parameters for Estimating Right Atrial Pressure:A Need for Standardization?.Journal of the American Society of Echocardiography, (2015; 28(12), pp.1420-1427

Waikar SS, Liu KD, Chertow GM, Diagnosis, epidemiology and outcomes of acute kidney injury.Clin J Am Soc Nephrol.2008;3:844-861.

Zengin, S., Al, B., Genc, S., Yildirim, C., Ercan, S., Dogan, M. and Altunbas, G.Role of inferior vena cava and right ventricular diameter in assessment of volume status: a comparative study.The American Journal of Emergency Medicine, (2013, 31(5), pp.763-767.). 